\title{
DOMESTIC ENERGY UTILIZATION AND POTENTIALS OF ALTERNATIVE SOURCES OF ENERGY IN MUBI METROPOLIS
}

\author{
Bulus Luka Gadiga ${ }^{1}$, Kevin Ferdinand Jigumtu ${ }^{2}$ and Hajjatu Tammi ${ }^{3}$ \\ ${ }^{1,2,3}$ Department of Geography, Adamawa State University, Mubi, Nigeria \\ Email : bulgami@gmail.com,bulga_mi@yahoo.com
}

Received: 25 July 2018/Revised: 13 August 2018/Accepted: 18 August 2018/Published online: 28 August 2018

\begin{abstract}
The Study investigates domestic energy utilization and potentials of alternative sources of energy in Mubi metropolis of Adamawa State. To achieve the objectives of this study, data were collected using questionnaire. A total of 108 sets of questionnaire were retrieved and analyse using descriptive statistics. Some of the data collected from respondents include; types of energy used for various purposes, factors that influence such use and preferences for the different types of energy. Other information which cannot be collected using questionnaire were obtained from published and unpublished materials. The findings show that households rely more on fuel-wood. Economic factors were found to influence the choice of energy used in homes. Solar energy and wind energy have high potentials as alternative energy source that will help in mitigating climatic change. The study concludes that households in Mubi metropolis tends to climb the energy ladder from low grade energy types to modern energy when income increases and such energy are made available. The study recommends that households be sensitized on the health and environmental effects of traditional energy. Households should be encouraged to use modern and alternative sources of energy in order to mitigate climate change. Such energies should also be made affordable and available since majority of the respondents were willing to switch when made affordable.
\end{abstract}

Keywords: Domestic energy, alternative energy, climate change, firewood.

\section{Introduction}

Domestic energy utilization is the total amount of energy used in a household. The amount of energy used per household varies widely depending on the standard of living of a country, the climate, the age of the head of household and type of residence (Palmer, 2004). Energy is a basic necessity of life for meeting domestic, social and industrial needs. Adequate and regular supplies of energy for both industrial and domestic purposes are prerequisites for socio-economic progress and overall development. Energy is required at all times for meeting various purposes especially at the household levels. Life can become difficult without the availability of adequate and regular energy supply for domestic needs. Energy for domestic 
purposes is determined by two major factors: availability and affordability (Momodu, 2013). This implies that energy must be readily available and at an affordable price that is within the reach of the people especially the poor. Making energy available to all and sundry in a particular society is a measure of the level of economic development of that particular society. For example, in advanced economies, majority of their population have access to cheap and affordable energy supply because of their technological advancement (Momodu, 2013). In such clime, the necessary energy infrastructures are available while the costs of energy are affordable by the majority of the people.

The reverse is however the case with people living in low income country like Nigeria, where the purchasing power of large proportion of the populace is low while necessary energy infrastructure is not in place. Thus, majority of the people do not have access to energy sources of their choice. In addition, there is inadequate energy infrastructure and inadequate energy supply. This further compounds the problems of energy availability. Overall, most of the developing nations do not have access to cheap, reliable and environmentally friendly energy sources.

In terms of utilization, household energy accounts for about $40 \%$ of the total energy consumption in developing countries (Obueh, 2008). Households use energy for lighting, heating, cooling, ironing, food and drinks preservation, powering electronic devices, cooking and vacuum cleaning. The rural dwellers, whose needs are often basic, depend to a large extent on the traditional sources of energy for their domestic energy requirements while the majority of the urban dwellers depend on traditional energy sources and fossil fuels. However, the high level of poverty and other socio-economic problems inhibit both the rural and urban dwellers from having access to adequate and reliable sources of energy for domestic purposes.

In terms of energy availability, there are various alternative energy sources in Nigeria such as wind, biomass and solar, which if properly harnessed will alleviate energy problems of the people most especially for their domestic consumption. Obviously, Nigeria is naturally endowed with oil and gas and depends on it for her economic development. For example, oil accounts for $80.5 \%$ of national revenue (CBN, 2009). These two energy sources are the major export commodities that provide foreign exchange earnings for the country. Oil and gas also play major role in meeting energy needs of the various sectors of the nation's economy. Studies by Climate Change Network Nigeria (CCNN) (2003) reveal that the combustion of fossil fuels is not the only anthropogenic source of carbon dioxide. When ecosystems are 
altered and vegetation is either burned or removed, the carbon stored in them is released to the atmosphere as carbon dioxide. Currently, up to a quarter of the carbon dioxide emitted to the atmosphere can be attributed to land use change. Concentrations or emission of greenhouse gases and especially carbon dioxide have risen over the past two hundred and fifty years, largely due to the combustion of fossil fuels for energy production. Carbon dioxide in the atmosphere has risen from about 270 parts per million (ppm) Giga tons to about 370 ppm Giga tons (CCNN, 2003). Environmental problems like deforestation, desertification and drought will be the order of the day as a result of the emission of carbon dioxide and other toxic and harmful gases if these traditional sources of energy like firewood are frequently used. Fossil fuels, coal, natural gas, and oil, produce most of our electricity but come with significant and harmful consequences. They produce the vast majority of global warming emissions. They release toxic chemicals that pollute our air and water. And they have adverse, and costly, effects on public health (UCS, 2015).

Climate change and climate variability in Nigeria have become issues of considerable concern. Evidences from studies have revealed that the country is vulnerable to the impact of climate change. Instrumental observations over the past 150 years show that surface temperatures have risen globally, with important regional variations. In Nigeria, temperatures have been on the increase in the last five decades and have been very significant since 1980s. After the drought of 1983, temperatures have been above normal except in 1989 and 1992. The 55-year $(1951-2005)$ linear trend indicates a change of $1.01(0.52$ to 1.5$){ }^{\circ} \mathrm{C}$. The linear warming for the same period of 30-year averages on a decadal slice further reveal changes in temperature by an average of $0.2^{\circ} \mathrm{C}$. Temperature anomalies over the country show that except in1973 when the country experienced a significant drought, temperatures were below normal between 1951 and 1978. From the 1980s upward, temperatures have been above normal by as much as $2^{\circ} \mathrm{C}$ in 1998 which was considered as the hottest year in instrumental records in the country (Federal Ministry of Environment, 2014).

A study conducted by New et al. (2006), from 1961 - 2000, has shown that there was an increase in the number of warm spells over West Africa and a decrease in the number of extreme cold days. There exist a number of inter-annual fluctuations observed in the annual rainfall over the country which is responsible for dry and wet years or extreme climate events such as drought and flood. The fluctuations during the first relatively wet period which occurred between 1951 and 1968 had high values of rainfall in 1954, 1955, 1957 and 1963. The lowest value of rainfall during this period was in 1958. The period 1970 - 1990 was dry except between 1978 - 1980 and coincided with the Sahelian droughts of early 1970s and 
1980s. From 1990s to present, rainfall has been above normal. However, rainfall was much better in the 1990s than the present. The general trend indicates a decline in rainfall over the country even though some locations may experience better rainfall than what has been expressed for the country (Federal Ministry of Environment, 2014). This will eventually have negative consequences on the economy of the country as majority of the people depend on rain-fed agriculture as their main source of income.

The use of alternative sources of energy is desirable in tackling the contemporary global challenge of climate change and environmental degradation. Hence, this study attempts to assess the potentials of alternative sources of energy in order to contribute to global efforts in mitigating climate change.

\section{The Methods}

\subsection{Study Area}

Mubi as a geographical area falls within two major local government areas, Mubi north and Mubi south. The Metropolis lies approximately between latitude $10^{\square} 14^{\prime} 30^{\prime \prime}$ and $10^{\square} 18^{\prime} 08^{\prime \prime}$ north of the Equator, and between Longitude $13^{\square} 13^{\prime} 09^{\prime \prime}$ and $13^{\square} 17^{\prime} 14^{\prime \prime}$ East of the Greenwich meridian with the Yadzeram River cutting across it (figure 1). Mubi metropolis is situated at the foot of the Mandara mountain ranges, and extends westwards. Mubi north and south local government areas share international boundary with the Republic of Cameroun on the eastern parts. Mubi has a land area of $4728.77 \mathrm{~km}^{2}$ with a population of 151,515 (NPC Yola 2006).

Mubi region has tropical wet and dry type of climate coded as Aw in the Koppen's climatic classification. Mubi has one of the tropical African Savanna climate where temperature gradually increases from January to April with seasonal maximum occurring in the month of April. Temperature declines slightly as rain set in due to the effect of cloudiness, increasing again after the cessation of rain in the month of October to November. Relative humidity tends to be low between January and March; and increases from April to reach the maximum in August following the movement of the Intertropical Convergence Zone (ITCZ). 


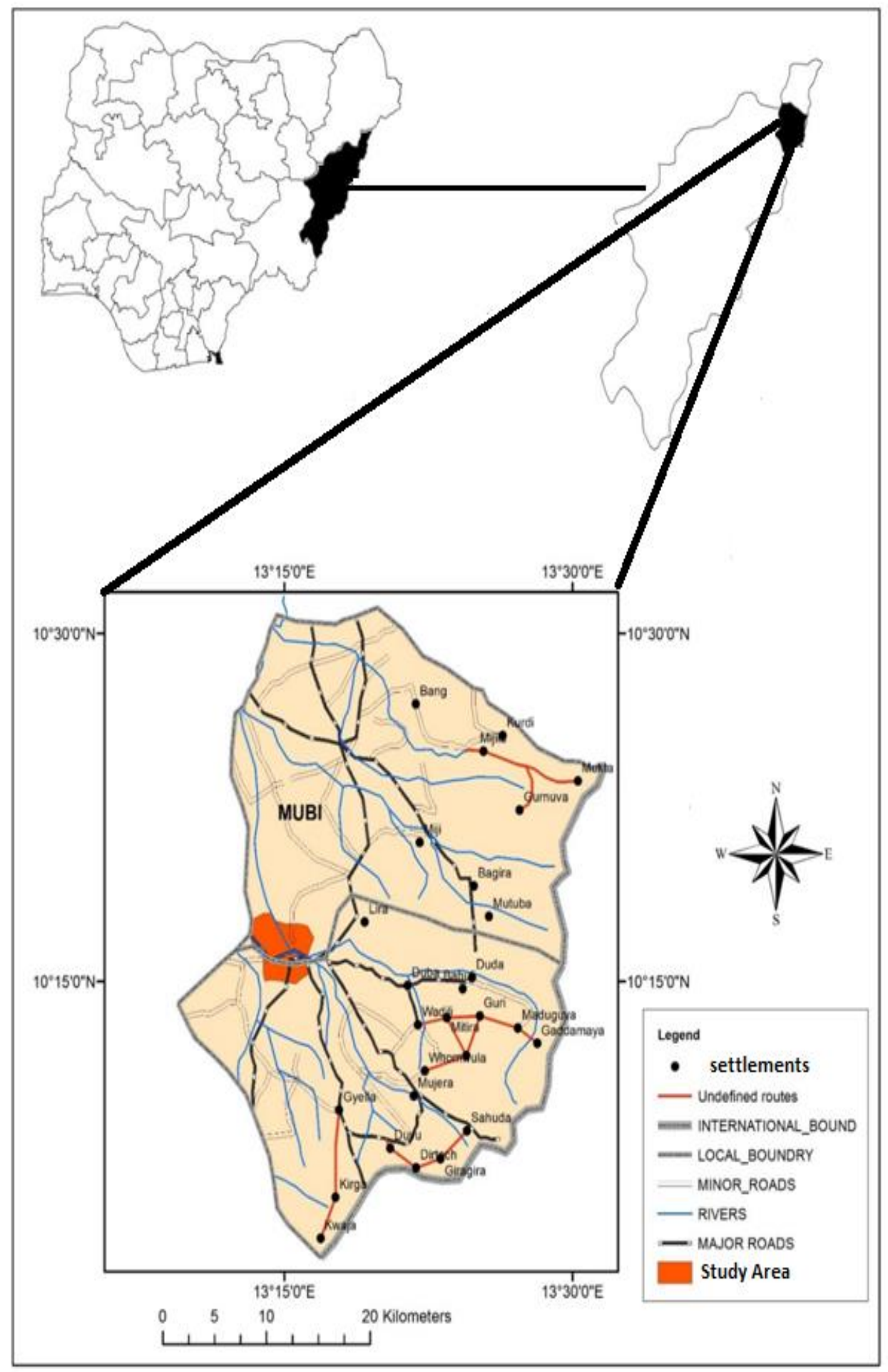

\section{Figure 1: The Study Area}

\subsection{Analysis of Data}

To achieve the objective of the study, the following information were acquired using questionnaire; types of energy used for various purposes, factors that influence such use and preferences for the different types of energy. Other information which cannot be collected 
using questionnaire were obtained from published and unpublished materials. A total of 108 sets of questionnaire were retrieved and analyze using descriptive statistics. Four wards were selected from the study area which was categorized into residential zones; very low, low, medium and higher-class residential zones. The purpose of using different zones of the study area is to determine variation in energy utilization. The study also assesses the potentials of alternative energy sources in generating electricity in order to mitigate climate change by reducing emission of $\mathrm{CO}_{2}$ as a result of fossil fuels and fuelwood consumed per household.

\section{Results and Discussion}

The sets of questionnaire were administered in the four selected residential zones (wards) in study area. Out of the 120 questionnaire administered, 108 were retrieved and analyzed. Table 1 gives the distribution of questionnaire in each ward.

Table 1: Questionnaire return rate

\begin{tabular}{|c|c|c|}
\hline Ward & Distributed & Retrieved \\
\hline Wuro Patuji & 30 & 24 \\
\hline Barama & 30 & 27 \\
\hline Kolere & 30 & 29 \\
\hline Lamurde & 30 & 28 \\
\hline Total & 120 & 108 \\
\hline
\end{tabular}

Source: Field Survey, 2018.

\subsection{Categorization of Energy Used by Household}

The results of data collected on household energy use with their sources are presented in Table 2. Mean and percentages were used in determining the general responses of the respondents. 
Table 2: Types of Energy used by Households

\begin{tabular}{lcccccccc}
\hline Energy/utility & Cooking & $\%$ & Ironing & $\%$ & Lighting & $\%$ & Cooling & $\%$ \\
\hline Electricity & 0 & 0 & 7 & 5.5 & 35 & 32.4 & 41 & 37.9 \\
Gas & 7 & 6.5 & - & - & 0 & 0 & - & - \\
Kerosene & 17 & 15.7 & - & - & 40 & 37.0 & - & - \\
Firewood & 44 & 48.2 & - & - & 4 & 3.7 & - & - \\
Charcoal & 32 & 29.6 & 99 & 91.6 & - & - & - & - \\
Candle & - & - & - & - & 29 & 26.9 & - & - \\
Petrol/diesel & 0 & 0 & 2 & 1.9 & 0 & 0 & 67 & 62.1 \\
\hline TOTAL & 108 & 100 & 108 & 100 & 108 & 100 & 108 & 100
\end{tabular}

Source: Field Work, 2018

The Table shows that in the study area electricity was not usually used for cooking $(0 \%)$ due to epileptic power supply from the national grid. Only $6.5 \%$ of the respondents indicated to using gas, $15.7 \%$ use kerosene stove, while firewood is the dominant type of energy use for cooking (48.2\%) followed by charcoal which has $29.6 \%$. The energy type that is mostly used for ironing is charcoal (91.6\%), electricity from the national grid is the second important energy used for ironing $(6.5 \%)$ and electricity generated using petrol/diesel generators is the least used energy (1.9\%) for ironing in Mubi metropolis. For household lighting, bush lambs using kerosene and generators (petrol/diesel) are the frequently used energy types for lighting with $37 \%$ of responses, electricity is the second frequently used energy for lighting (32.4\%), candle (26.9\%) and the least is wood product $(3.7 \%)$. The energy type attributable for cooling in most households is petrol/diesel powered generators $(62.1 \%)$ while electricity from the national grid (37.9\%) is also used.

The findings of this research revealed that the most frequently used energy type for cooking in households is firewood followed by charcoal. The energy type used for ironing is charcoal. In most households, kerosene/petrol powered generators ranked high in the use of energy for lightning in the area. For cooling in the area, petrol/diesel ranked the most used. This shows that, the most frequently used energy type in Mubi metropolis is firewood/charcoal followed by petrol/diesel. The findings of this study agrees with the position of World Bank, (2005) and NEC, (2006), which stated that in Nigeria, traditional energy sources accounts for over $70 \%$ of domestic energy supply. The use of this type of energy could be attributed to the fact that the traditional energy sources are more accessible 
energy sources. With the current pressure heaved on the firewood and other wood product in the area, there is no doubt that the area will soon start experiencing a dramatic change in its micro climatic conditions.

\subsection{The Factors Influencing the Choice of Energy Used by Households}

Factors that influence the choice of different energy types used in households are collected from respondents. Table 3 presents the results of respondents that strongly agree and agree that price, season, accessibility and culture influences the choice of used by households and also those that disagree and strongly disagree to the influence of these factors.

Table 3: Factors Influencing the Choice of Energy Used by Households

\begin{tabular}{lcccccccc}
\hline \multicolumn{1}{c}{ Response } & $\begin{array}{c}\text { Increase in } \\
\text { price }\end{array}$ & $\mathbf{\%}$ & Seasonality & $\boldsymbol{\%}$ & Accessibility & $\boldsymbol{\%}$ & Cultural belief & $\%$ \\
\hline Strongly agree & 69 & 63.9 & 70 & 64.8 & 83 & 76. & 28 & 25.9 \\
Agree & 29 & 26.9 & 30 & 27.8 & 18 & 16. & 18 & 16.7 \\
Strongly & 1 & 0.9 & 0 & 0 & 2 & 1.8 & 27 & 25 \\
disagree & 9 & 8.3 & 8 & 7.4 & 5 & 4.6 & 35 & 32.4 \\
$\begin{array}{l}\text { Disagree } \\
\text { TOTAL }\end{array}$ & 108 & 100 & 108 & 100 & 108 & 100 & 108 & 100 \\
\hline
\end{tabular}

The result in Table 3 shows that $63.9 \%$ strongly agree, $26.9 \%$ agree, 0.9 strongly disagree and $8.3 \%$ disagree that price of energy affects their choice of energy as a result, it also shows that $64.8 \%$ strongly agree, $27.8 \%$ agree, strongly disagree $0 \%$ and $7.4 \%$ disagree that seasonality affects their choice of energy, it also shows that $76.9 \%$ strongly agree, $16.7 \%$ agree, strongly disagree $1.8 \%$ and $4.6 \%$ disagree that the accessibility in terms of availability and affordability affects the choice of energy they use. For example the accessibility of firewood in their environment has greatly influence the way has been used in the study area. However, it shows that $25.9 \%$ strongly agree, $16.7 \%$ agree, strongly disagree $25 \%$ and $32.4 \%$ disagree that cultural belief and preference affects the energy used for cooking and other activities.

Accessibility of the different energy types was found to be a strong determinant of its use. Majority of the households agree that firewood is collected for free and this influence its 
high usage in the area, while some households resort to the use of firewood and charcoal owing to its relative cheapness.

Price of energy, whether it is very affordable or not its availability and accessibility can also determine its use. Income is also a major determinant of the type of energy been used in the area as high and medium income earners tends to climb the energy ladder from low grade energy types to modern energy. For example, the use of charcoal-iron is substituted with electric-iron when income improves.

\subsection{Carbon dioxide Emission by Firewood consumed in Mubi Metropolis}

ETB (2011) shown that firewood when used as a fuel emits the highest $\mathrm{CO}_{2}$ compared with other fuels $\left(0.39 \mathrm{~kg} \mathrm{CO}_{2} / \mathrm{kwh}\right)$ thereby contributing to global warming. The combustion of $1 \mathrm{~kg}$ of wood generates between 1.65 and $1.80 \mathrm{~kg}$ of carbon dioxide depending on the species used (Halava, 2013; Kaltimber, 2017). Thus, the approximate emission in Mubi was calculated based on $1.73 \mathrm{~kg}$ of $\mathrm{CO}_{2}$ per $\mathrm{kg}$ of firewood.

Table 4 Emission of Carbon Dioxide by Quantity of Fuel Wood consumed in Mubi

\begin{tabular}{lccccl}
\hline Wards & $\begin{array}{c}\text { Firewood } \\
\text { consumed } \\
\text { daily kg }\end{array}$ & $\begin{array}{c}\text { Fixed } \\
\text { emission of } \\
\text { Co2 kg }\end{array}$ & $\begin{array}{c}\text { No. of } \\
\text { household }\end{array}$ & $\begin{array}{c}\text { Mean } \\
\text { monthly } \\
\text { firewood } \\
\text { consumption }\end{array}$ & $\begin{array}{l}\text { Mean } \\
\text { monthly } \\
\text { emission of } \\
\text { CO2 } \mathbf{~ k g}\end{array}$ \\
\hline Kolere & 2.6 & 1.73 & 1,346 & 104,988 & 181629.24 \\
Lamurde & 2.1 & 1.73 & 455 & 28,665 & $49,590.45$ \\
Barama & 1.7 & 1.73 & 792 & 40,392 & $69,878.16$ \\
Wuro & 3.4 & 1.73 & 1275 & 130,050 & $224,986.5$ \\
patuji & & & & & \\
\hline
\end{tabular}

From the Table 4, wuro patuji consumes the highest wood per household per day (3.4kg) which approximately emits $224,986.5 \mathrm{~kg}$ of $\mathrm{CO}_{2}$ monthly. Kolere consumes an average of $2.6 \mathrm{~kg}$ of firewood per household per day and with the total of 1346 households it therefore consumes a total $181,629.24 \mathrm{~kg}$ of firewood monthly which translates into 104,988 $\mathrm{kg}$ of $\mathrm{CO}_{2}$. Lamurde consumes $2.1 \mathrm{~kg}$ of wood per household daily which emits $49,590.45 \mathrm{~kg}$ of $\mathrm{CO}_{2}$ and Barama with the least firewood consumption $(1.7 \mathrm{~kg})$ emit $69,878.16 \mathrm{~kg}$ of carbon dioxide monthly. 
This shows from the information obtained, that a total household of 26,378 are found in the study area (Mshelia, 2015). Therefore, the households in Mubi daily consume an average of $64,626.1 \mathrm{~kg}$ of wood which emits $111,803.15 \mathrm{~kg}$ of carbon dioxide into the atmosphere daily and 3,354,094.59 kg monthly.

Therefore, targeting alternative energy sources will address about $30 \%$ of the carbon dioxide emissions in the area (CCNN, 2003). For example, the use of renewable energy for electricity generation does not cause additional carbon dioxide emissions, and is sustainable into the future. The major challenges with the use of renewable sources of energy are the cost, intermittency of supply, and distance between the resources and the end user. Some possible renewable energy sources in the area are solar power, wind power and rooftop photovoltaic.

Table 5: The Preferences of Alternative Energy Sources in Mitigating Climate Change.

\begin{tabular}{lcc}
\hline \multicolumn{1}{c}{ Response } & Frequency (f) & Percentage (\%) \\
\hline Prevent soil erosion & 16 & 14.8 \\
Minimal emission of carbon dioxide & 47 & 43.5 \\
Available & 15 & 13.9 \\
Cheap & 11 & 10.2 \\
Reduces deforestation & 19 & 17.6 \\
\hline
\end{tabular}

Data presented on the preferences of alternative energy sources in mitigating climate change showed that $43.5 \%$ prefers alternative energy source because they emit less carbon dioxide than firewood while $17.6 \%$ prefer alternative energy source because it reduces deforestation, $14.8 \%$ said it protect soil against erosion, $13.9 \%$ said is available in the environment and $10.2 \%$ said it is healthier to the environment.

The information given by the respondents on the alternative sources of energy shows that if the energy is made available and affordable they are willing to switch to it which will help to mitigate the emission of carbon monoxide and carbon dioxide. According to CCNN, (2003), when alternative energy sources or modern energy sources are made available and affordable, it will reduce about $111,803.15 \mathrm{~kg}$ of carbon dioxide emitted daily into the atmosphere thereby reducing global warming. Hence, alternative energy is the answer to our global climatic crisis. Solar and wind power are the main sources of renewable energy that this study considers as suitable to the study area. Studies have shown that areas with a total 
solar output of $5.2 \mathrm{kw} /$ day and wind speed of $60 \mathrm{kw}$ will be sufficient to generate power for domestic use (UCS, 2015).

Renewable energy resources like wind and solar power generate electricity with little or no pollution which could reliably and affordably provide energy mix for the area thereby reducing the emission of greenhouse gas (UCS, 2015). The use of alternative sources of energy can globally reduce deforestation annually from 400,000 to about 120,000 hectares this is because trees are being used for other uses apart from energy (i.e. in construction, furniture etc.) which will eventually checkmate to a reduced level soil erosion and deforestation (CCNN 2003).

\subsection{Potentials of Alternative Sources of Energy in the Study Area}

a. Solar energy

Solar energy will be ideal for household power generation in the study area; this is because the area receives an average of 9 hours of solar radiation which translate to about $5.25 \mathrm{kw} / \mathrm{m}^{2}$ energy (Osueke and Ezugwu, 2011). Therefore, Mubi can be said to have high potentials for the development of solar energy which can generate electricity to be used domestically.

\section{b. Wind energy}

Large utility-scale wind turbines range in size from 50 kilowatts to over four megawatts. Smaller wind towers (under $50 \mathrm{~kW}$ ) are suitable for residential and agricultural use. For wind energy system to function effectively, certain conditions like wind speed and space most be put into consideration. Base on this information, the location of Mubi close to Mandara highlands makes it ideal for wind powered energy with an average speed of $60 \mathrm{Kw}$ can rotate turbine that can generate electricity for domestic purposes (Oyeneye, 2004). Wind power is a totally renewable energy source with no greenhouse gas emissions. As one of the alternative source of energy, wind towers can be installed to generate electricity which will go a long way in mitigating $\mathrm{CO}_{2}$ emission in Mubi. Wind energy is clean, non-polluting, and capable of providing enough electricity to power a household.

\section{Conclusion}

The findings revealed that households in Mubi Metropolis responded differently in their energy use pattern. The choice of energy use can be related to season, accessibility, location, income, and energy price. The study shows that traditional sources of energy are commonly used for domestic purposes. Firewood accounts for the most frequently used 
source of energy in the area. Other sources of energy like; fossil fuel (kerosene, petrol, diesel and gas) and charcoal are also used in the area.

Households in Mubi Metropolis responded positively to the use of modern energy for cooking and non-cooking activities. However, they are constraint by the affordable, available of these cleaner energies. Making modern energy available and affordable as well as sensitizing households on the impact of traditional energy use on the environment will help ensure a secured and safe environment. Based on these findings the study concludes that households in Mubi area tends to climb the energy ladder from low grade energy types to modern energy when income increases and such energy are available. The high dependence of most households on low grade energy types has environmental and health implications especially against the backdrop of forest degradation and deforestation amidst the threats of climate change.

\section{References}

CBN (2009). Statistical Bulletin, Central Bank of Nigeria: Volume 20, December 2009

Climate Change Network Nigeria (CCNN, 2003) Monitoring Nigerian climate change. www.ccnnigeria.org accessed on February, 2018

DECC, (2013) The UK low carbon transition plan: national strategy for climate and energy. Presented to Parliament pursuant to Sections 12 and 14 of the Climate Change Act 2008, TSO

ETB (2011) Engineering Tool Box. http://www.engineeringtoolbox.com. Accessed May 2017

Federal Ministry of Environment (2014). Nigeria's Second National Communication Under TheUnited Nations Framework Convention on Climate Change. Abuja, Nigeria.

Halava, Satu (2013) Carbon Footprint of Thermowood. unpublished project, Satakunnan University of Applied Sciences. Accessed on 13 ${ }^{\text {th }}$ August, 2018 from https://www.theseus.fi/bitstream/handle/10024/63624/Halava_Satu.pdf;sequence=1

Kaltimber (2017) How much CO2 is stored in $1 \mathrm{~kg}$ of wood? http://www.kaltimber.com/blog/2017/6/19/how-much-co2-is-stored-in-1-kg-of-wood accessed on 11th August, 2018.

Mshelia, A. D (2015). Seasonal Variations of Household Solid Waste Generation in Mubi, Nigeria. International Journal of Innovative Education and Research. Vol. 3, No. 5 
Momodu I. M., (2013). Domestic Energy Needs and Natural Resources Conservation: The Case of Fuelwood Consumption in Nigeria. Mediterranean Journal of Social Sciences, Vol 4 No 8. 27-33

NEC, (2006) National Emission Ceilings for Certain Atmospheric Pollutants. Ministry of Housing, Spatial Planning and the Environment, The Hague, Netherlands

New, M., Bruce Hewitson, David B. Stephenson, Alois Tsiga, Andries Kruger ....Robert Lajoie (2006): Evidence of trends in daily climate extremes over southern and West Africa, J. Geophys. Res., 111, D14102, doi: 10.1029/2005JD006289.

Nigeria Energy Commission, (2006) Report of survey of energy utilization in the informal sector: A case study of the FCT, Federal Ministry of Power Technical Report. September, 2006.

Obueh, J. (2008), "The Ecological Cost of increasing Dependence on Biomass fuels as Household Energy in Rural Nigeria": Lessons from Boiling Point No. 44, GTZ/ITDG. Laurent Cousineau copyright 2011-2017, climate change guide.

Osueke C. O and C. A. K. Ezugwu (2011) Study of Nigeria Energy Resources and Its Consumption. International Journal of Scientific \& Engineering Research, Vol. 2, (12)

Oyeneye O.O., (2004) Socio-economic influence on policies of Power Deregulation, Proc 20th National Conference of the Nigeria Society of Engineering (Electrical Division), October 6th to 7th, 2004, Pp.1-15

Palmer J, Cooper I. (2014) United Kingdom energy housing fact file 2013; 2014.

Union of Concerned Scientists (UCS), (2015) Science for a healthy planet and safer world. 2016-2020 Strategic Plan

World Bank, (2005). “Household Energy Use in Developing Countries"' (series No.5). Washington D.C., U.S.A: retrieved on August 16, 2012 from ESMAP Report.http://www.Worldbank.org./esmap/. Accessed on July 10th, 2012. 